Светлана Чернова

Новосибирский государственный университет Гуманитарный институт

Центр международных учебных программ sochernova@mail.ru
УДК 811.161.1:371

https://doi.org/10.18485/slavistika.2019.23.2.12

Стручни рад

примљено 04.03.2019.

прихваћено за штампу 10.10.2019.

\title{
ОБ ЭФФЕКТИВНОСТИ ОБУЧЕНИЯ РУССКОМУ ЯЗЫКУ КАК ИНОСТРАННОМУ
}

В данной статье анализируются способы оптимизации обучения иностранных студентов русскому языку: помощь в формулировке цели изучения русского языка, соединение обучения с позитивными эмоциями, отработка правильного интонирования и паузирования на материале эталонных образцов русской поэзии, создание грамматических алгоритмов как точек опоры для формирования новых языковых навыков, увеличение эффективности обучения за счёт сочетания сознательного и бессознательного, обязательного и «случайного», особенности работы над ошибками.

Ключевые слова: эффективность, эмоции, алгоритмы, сочетания, ошибки.

This article is devoted to the methods of optimization of teaching Russian as a second language: helping to formulate the purpose of learning Russian, combining learning with positive emotions, intonation and pausing practice through the best examples of Russian poetry, creating grammatical algorithms as reference points for the formation of new language skills, learning efficiency enhancement through a combination of conscious and unconscious, binding and "accidental", particular features of correcting mistakes.

Keywords: efficiency, emotions, algorithms, combination, mistakes.

Эффективное обучение - это процесс получения новых знаний с максимальным качеством, это высшая степень усвоения полученных знаний. За одно и тоже время обучения можно получить абсолютно разный результат: «предмет методики обучения русскому языку как иностранному — это оптимальная система управления учебным процессом, т. е. система, направленная на наиболее эффективное овладение учащимися русским языком» (Леонтьев 1988: 5-6).

Эффективность обучения русскому языку как иностранному (РКИ) - обширнейшая тема. В этой статье мы постараемся внести свою посильный вклад в решение данного вопроса.

На наш взгляд, первым показателем эффективности учебного процесса является активность студента на уроке РКИ. Усталость учащегося во время занятия свидетельствует о его недостаточной заинтересованности в том, что происходит на уроке; это обычно бывает, если знания усваиваются пассивно, т. е. если обучающийся недостаточно вовлечен в материал урока. Студенты, раскрываюшие и развивающие свой потенциал, увлечённые работой с «текстами плюс ситуация», т. е. дискурсами (Попова 2014: 641-643), показывают в обучении русскому языку прекрасные результаты. К примеру, отработка правильного интонирования и паузирования может проходить на материале эталонных образцов русской поэзии, студенты с удовольствием читают стихи «вместе» с современными актерами; вообще, выучивание наизусть через имитацию и «ли- 
цедейство» - замечательная учебная практика, и благо, что в филологии и методике РКИ накоплен большой материал по анализу художественного текста (Кулибина, 2000), что же касается художественного чтения, владения речевым аппаратом, то тут преподаватель может учится учить у специалистов в других областях знания, это актерское мастерство, оперное пение, логопедия (мастер классы, тренинги, лекции и т.д). Преподаватель РКИ является для студентов проводником в увлекательном путешествии в русский мир: мир русского языка, русской словесности, русской культуры в целом и т.п. И студентам нравится это совместное «путешествие».

Активность студента на уроке поддерживается преподавателем РКИ, требования к которому описаны в методической литературе (Молчановский 2004: 102-124). Хотелось бы выделить главное, а именно: развитие преподавателем у студентов позитивных установок на овладение русским языком, направление фокуса внимания учащихся на то, что получается, помощь в формулировке цели изучения русского языка и в понимании, удовлетворению каких потребностей способствует освоение русского языка, помощью в осознании индивидуального типа мотивации. Преподаватель должен стремиться сделать процесс обучения интересным и полезным для каждого студента. Это особенно актуально для университетов, где в одной учебной группе по русскому языку оказываются студенты одного уровня, но разных специальностей, национальностей, студентов, обладающих разными способностями, движимых разной мотивацией, имеющих разный опыт обучения и проживания в России. Демократичный стиль поведения преподавателя, проявляющего интерес к тому, что говорит каждый студент, - гарантия того, что студент не замолчит и не потеряет интерес к языку. Увлеченность преподавателя, позитивные эмоции преподавателя по поводу того, что происходит на уроке, также передаются студентам.

Развитие «чувства языка» связано с накоплением практического опыта активного использования русского языка (Федоренко 1964: 11-13), в связи с этим целесообразно: при чтении текстов обучать студентов прежде всего фокусировать внимание на понятном (для более точного понимания и для интеграции ранее усвоенных знаний, умений; это, разумеется, не отменяет детального анализа текста), максимально использовать догадку и интуицию, при переводе слов обращать внимание учащихся на морфемную структуру, учить до использования двуязычного словаря анализировать слово в его контексте, изучать со студентами фразеологические единицы, сравнивая с подобными в их родных языках, выполнять упражнения «конкретное - абстрактное» (например, слово - ритмическая модель), выполнять упражнения, формирующие представления о парадигматических и синтагматических связях на всех уровнях языковой системы и т. п. При этом, получая обратную связь от студентов, преподаватель постоянно варьирует набор языковых, речевых и коммуникативных заданий для каждой группы и каждого студента.

Показателями эффективности обучения русскому языку также являются быстрое усвоение студентами изучаемого материала, скорость овладения языковыми и речевыми навыками, а также прочность этих навыков. Важным вопросом является разрушение неправильных языковых / речевых привычек, создание правильных языковых / речевых навыков. 
Если учебная группа состоит из студентов одной национальности, то работа по формированию новых грамматических навыков строится в зависимости от наличия / отсутствия изучаемой грамматической категории в родном языке учащихся, её «наполненности». Начиная работу в аудитории определенного типа (национальность, уровень обучения, уровень знания русского языка и т.д.) преподаватель планирует проработку определенных «горячих точек», предлагая отработанные алгоритмы действий, дабы усилить транспозицию (положительный перенос умений и навыков в речь в другом языке) и предупредить отрицательную интерференцию (Успенский 1970: 9).

Исключительной является ситуация, когда студенты одной национальности вместе изучают русский язык от уровня к уровню. В реальности в составе одной языковой группы оказываются студенты различных национальностей, которые осваивали русский язык в разное время в разных университетах мира в составе различных учебных групп. Каждый обучающий невольно несёт собственный багаж ошибок: «ошибки из-за недостаточно прочных навыков», «ошибки в результате неправильного понимания или плохого застарелого навыка» (Цветкова 1964: 30-31).

Перед преподавателем РКИ стоит задача «аннулировать» неправильные языковые привычки студентов, сформировать новые правильные языковые навыки. Работа по созданию новой нейронной цепочки состоит в последовательном формировании нового алгоритма действий.

Единицей обучения грамматическому аспекту речи в практическом курсе языка является речевой образец - предложение, построенное на основе синтактико-морфологической структуры, в единстве всех его аспектов: фонетического, графического. лексического и грамматического (Капитонова и др. 2006: 136).

Теоретико-практический путь овладения грамматическими навыками описан в методической литературе (Щукин 1990: 71-72). Речевые образцы-предложения служат учащимся моделями для построения других предложений по аналогии (продуктивные грамматические навыки), обеспечивают узнавание и понимание грамматических структур (рецептивные грамматические навыки).

Опыт показывает, что использование эмоционально заряженных речевых образцов существенно сокращает теоретико-практический путь овладения грамматическими навыками.

Эмоции необходимы для успешного обучения. Они способствуют лучшему усвоению материала, т.к. связаны с восприятием (студенты с позитивным эмоциональным настроем открыты к получению знаний, дают более эффективную обратную связь), с памятью (позитивные эмоции улучшают запоминание информации и её последующее извлечение) и с вниманием (положительные эмоции позволяют учащимся дольше концентрироваться) (Шаховский 2008). Если информация, которую надо запомнить, по каким-то причинам человеку неинтересна, необходимо целенаправленно сформировать соответствующую мотивацию.

Поэтому в качестве эмоционально заряженных речевых образов мы предлагаем студентам афоризмы (чёткие, легко запоминающиеся, краткие выражения мысли), забавные объявления и т.п. При этом мы предпочитаем индуктивный путь (от наблюдения к выводу) объяснения нового грамматического материала (разу- 
меется, совсем не исключая дедукцию). Изучая предложенные афоризмы, объявления, обучающиеся с помощью наводящих вопросов делают «самостоятельные» выводы. Творческие задания, использование эмоционально заряженных образов, «историй из жизни» вызывает у учащихся активную реакцию, любопытство, интерес, также способствует доверию и положительному отношению к предмету.

Чтобы проиллюстрировать написанное выше, рассмотрим причастия и деепричастия. Анализ ошибок показывает, что эти глагольные формы традиционно являются трудными для иностранных учащихся: они часто понимаются студентами формально, большое количество упражнений не гарантирует их правильное (без ошибок) употребление.

Значения русского деепричастия несовершенного вида и русских действительных причастий настоящего времени времени и прошедшего времени несовершенного вида выражает в английском языке одна глагольная форма Present Participle Active, в корейском языке различаются причастия не только прошедшего, настоящего, но будущего времени, отсутствует слово который, имеется более разветвлённая система деепричастий, в китайской грамматике формально отсутствуют классы слов, сходных с русским причастием, деепричастием (впрочем, как и грамматика вообе в общепринятом понимании) и т. д.

Перечислим главные опорные точки алгоритма изучения причастий и деепричастий.

Причастие и деепричастие. Общая опорная точка. Оформление пропозиции предикативной конструкцией - первичный способ её выражения, поскольку в этом случае имеет место симметрия между формальной организацией предложения и смысловой организацией. Однако такой способ выражения пропозиции не единственный. Пропозиция может быть выражена непредикативной конструкцией - вторичный способ. Пропозиция может быть оформлена деепричастием, деепричастным оборотом, причастием, причастным оборотом и т.д.

Причастие связано с определяемым словом присловной подчинительной связью.

Определительные отношения между компонентами в подчинительном словосочетании «прилагательное + существительное» (1), в словосочетании «причастие / причастный оборот + существительное» (2) и между частями сложноподчиненного предложения с придаточным присловными определительным с союзным словом который (3) аналогичны.

Деепричастие связано с предикативным центром предложения детерминантной необязательной связью.

Обстоятельственные отношения в «деепречастие / деепричастный оборот + предикат» и «придаточная предикативная конструкция времени / условия / причины / уступки + главная предикативная часть» аналогичны.

Чтобы студенты осознали, что такое причастие и деепричастие, сравниваем осложненные предложения с причастием и деепричастием с синонимичными им сложными предложениями.

Звери, живя вместе с нами, становятся ручными, а люди, общаясь друг с другом, становятся дикими (Гераклит) - Если / когда звери живут вместе с 
нами, они становятся ручныли, если / когда люди общаются друг с другом, они становятся дикими.

Звери, живущчие вместе с нами, становятся ручными, а люди, общающиеся друг с другом, становятся дикими. - Звери, которые живут вместе с нами, становятся ручными, а люди, которые общаются друг с другом, становятся дикими.

Дееепричастие.

Первая опорная точка. Чтобы учащиеся осознали, что деепричастие не обладает временным значением, приводим всю временную парадигму предложения с деепричастием.

Видя чужсе пороки, умный избавляется от своих (Публий Сир). - Видя чужие пороки, умный избавлялся от своих - Видя чужие пороки, умный будет избавляться от своих.

Вторая опорная точка. Осуществляем трансформацию деепричастных оборотов, выражающих временное, причинное, условное значения.

Сказав А, говори и Б-Когда сказал $A$, говори и Б-Так как сказал $A$, говори и Б-Если сказал А, говори и Б.

Третья опорная точка. Это трансформация деепричастных оборотов с уступительным / противительным значением.

Безумен тот, кто, не умея управлять собой, хочет управлять другими (Публий Сир) - Безумен тот, кто, несмотря на то, что не умеет управлять собой, хочет управлять другими - Безумен тот, кто, не умеет управлять собой, но хочет управлять другими.

К работе по трансформации причастий / деепричастий в афоризмах, объявлениях можно периодически возвращаться: знакомство с новым ярким афоризмом может быть необязательным (но не случайным, а запланированным элементом) любого урока, а именно афоризм может быть связан с изучаемым текстом, на работу с афоризмом можно выделить пять минут урока, чтобы дать студентам возможность передохнуть, например, на уроке по научному стилю речи, кроме того, афоризм можно обсудить, предварительно отчитав его во время фонетической зарядки, и т. д.

Четвёртая (или более ранняя) опорная точка. Студентам предлагается задание, способствующее пониманию деепричастия как гибрида глагола и наречия, обозначающего добавочное действие при предикате: микротекст Входя, лежит тряпка и примерно следующие вопросы:

Как Вы думаете, почему смеялись студенты, читая это объявление на двери комнаты в общежитии? Что студенты при этом делали?

Вопросы задаются до тех пор, пока студенты не скажут, что тряпка входить не может и что деепричастие и предикат связаны с одним грамматическим субъектом.

Разумеется, знание, которое «добыто самостоятельно», усваивается глубоко и надолго.

Причастие. На уроке РКИ мы практикуем различные способы проработки опорных точек. 
Привычная ситуация: приехавшие учиться в Россию студенты, изучали причастие в родной стране, неплохо делают трансформации причастных оборотов в придаточные определительные и наоборот, при этом иногда допускают ошибки. Наличие ошибок свидетельствует о том, что хотя студентами было выполнено большое количество упражнений, природа причастия не была «прочувствована».

Первая опорная точка. Первое, что студент должен понять, причастие - разновидность прилагательного, гибрид прилагательного и глагола, обособленное определение. И здесь мы можем пойти, например, таким путём.

Предлагается задание: описать похожие предметы, например, столы в аудитории, затем объяснить, чем они отличаются друг от друга. Так как столы в аудитории отличаются только положением в комнате, тем, что стоят в центре / у окна / у двери т. п., образуется ряд согласованных определений, выраженных прилагательными и причастиями, а также определительной предикативной конструкцией со словом который.

Вторая опорная точка и второй шаг. Студентам предлагается ответить на альтернативный вопрос: «Вы любящий или любимый сын? / любящая или любимая дочь?» Альтернативный вопрос предполагает выбор варианта. Далее следует вопрос-провокация (который зависит от ответа студента на предыдущий вопрос): «Неужели Вы не любите своих родителей?» / «Неужели родители Вас не любят?» Затем следует эмоциональная реакция студентов и ответы: «И любящий (ая), и любимый (ая)».

Обучение коммуникации на иностранном языке предполагает эмоциональную активность преподавателя и студентов. Делая процесс обучения ярче, интереснее для обучающихся, преподаватель на порядок лучше удерживает, направляет, усиливает внимание и память учащихся.

Многолетний опыт показывает, что данный речевой образец $B b$ любящий или любимый сын? / любящая или любимая дочь? усваивается быстро и надолго.

Третий шаг. Переходим от эмоций к логике. Преподаватель знакомит студентов с таблицей «Типы причастий». Студентам предлагается трансформировать аналогичный альтернативному вопросу грамматический речевой образец - афоризм Причина - объясняющее, но не объяснимое (А. Круглов) (Ответ: Причина - это то, что объясняет, но то, что невозможно объяснить).

Четвертый шаг начинается с обсудения афоризма Любящий человек живет в любящем мире...каждый встречный служит вам зеркалом (Кен Кейсмладший). При работе с этим речевым образцом мы обращаем внимание не только на суффиксы, но и на согласование причастий с определяемым словом в роде, числе и падеже.

Пятая опорная точка и пятый шаг. Введение причастий прошедшего времени. Студентам предлагается афоризм За каждым мужчиной, достигшим успеха, стоит гордящаяся им жена и удивленная тёща (Брукс Хейз). - За каждым мужчиной, который достиг успеха, стоит жена, которая им гордится, тёщз, которую он удивил.

Шестой шаг. Учащиеся самостоятельно записывают в таблицу «Типы причастий» афоризмы, объявления из предложенного им списка. 
Седьмой шаг - трансформация причастных конструкций в придаточные определительные конструкции, сравнение интенсивности обозначаемого признака в зависимости от типа конструкции и от места причастного оборота относительно определяемого слова, а также работа по устранению единичных ошибок, вызванных влиянием внутренней интерференции и состоящих в неверном согласовании который с существительным, определяемым причастием.

Восьмой шаг. Далее в рамках концентра более высокого уровня могут быть разобраны афоризмы, содержащие грамматикализованные причастия, причастия, входящие в состав оксюморона, напр.: А желающие - не хотят!; Следуюший поезд отошел десять минут назад; Политик думает о следующих выборах, государственный муж - о следующем поколении.

Коротко остановимся на роли ошибок в учебном процессе и способах их исправления: Когда, совершив ошибку, не исправил её, это и называется совершить ошибку (Конфуций). Мы согласны с афоризмом Конфуция. «Разбор полетов» - обязательный элемент работы на уроке РКИ; причем, ошибки не только не остаются незамеченными, они фиксируются преподавателем, студентами, исправляются самими студентами под «присмотром» преподавателя, а также служат материалом для упражнений, которые создаются преподавателем для работы на следующем уроке.

Наш опыт показывает, что ошибки обязательно должны исправляться (в противном случае неисправленное закрепляется в речи), не стоит откладывать работу над ошибками, желательно, чтобы учащиеся имели возможность лично их найти, исправить и постараться объяснить. В связи с этим сразу после текущей контрольной работы преподаватель выдает учащимся зелёные ручки (уже после преподаватель вносит свои правки красным цветом) и выводит на экран эталонно выполненную контрольную работу. Сверяя свои работы с образцом, студенты исправляют и объясняют ошибки, записывают верный вариант. Только затем преподаватель собирает работы студентов. Учащиеся получают две оценки: за контрольную работу и за проверку своей контрольной работы. Второй вариант работы над ошибками: проверив тетради для домашних заданий, преподаватель составляет «Листы ошибок», с которыми учащиеся, используя учебник, работают дома. Помимо того, «Листы ошибок» содержат материал для создания новых грамматических алгоритмов, корректировки уже используемых алгоритмов и грамматических опорных точек.

Кроме того, чтобы не перебивать студентов, мы разработали небольшую систему жестов (своеобразную жест-о-теку), дающую возможность преподавателю посылать студенту информацию о недочётах его речи, а учащемуся оперативно реагировать и исправлять ошибки, не прерывая речь. Разумеется, эта система охватывает только часть ошибок (глагольный вид, типы интонационных конструкций, номера падежей, порядок слов, некоторые фонетические ошибки, типы причастий, есть общий жест неправильно). Часть ошибок исправляется одногруппниками студента после его ответа, часть - студентом после наводящих вопросов преподавателя, оставшиеся ошибки записываются преподавателем на доске и анализируются всей группой. 
Студенты понимают, что контрольные работы - это способ утвердиться в верности своих знаний, способ обнаружить пробелы и вместе с преподавателем постараться их закрыть в будущем.

На наш взгляд, лекция - один из самых неэффективных способов обучения по причине своей средней продолжительности, монотонности, однообразному способу подачи информации (речь). Чередование разных видов учебной деятельности помогает преподавателю провести урок эффективно. Обычно преподаватель чувствует, когда пора сменить вид активности, например, ввести соревновательный компонент, предложить закрыть глаза и представить, о чём читает преподаватель, дать этимологическую задачку и т. д. Кроме того, в «копилке» преподавателя имеется множество забавных историй, рассказывающих о студенческих ошибках на разные правила фонетики, русской грамматики, лексики и т. д. Преподаватель может «вплетать» их в «ткань» урока. Например, история об испорченной лекции из-за единственной ошибки, допущенной в приветствии коллегам, - «Здравствуйте, уважаемые калеки!» - замечательно мотивирует учащихся к занятиям фонетикой. Сами студенты тоже постоянно пополняют «копилку» забавных ошибок (к примеру, история с использованием слова ребёнок в качестве формы единственного числа к ребята может быть как незапланированным, так и заранее спланированным элементом урока).

Пропускная способность памяти увеличивается и благодаря сочетанию сознательного и бессознательного в обучении, обязательного (работающего на цель данного урока) и «случайного», на первый взгляд не соответствующего теме, этапу урока (например, после подключения этимологической странички, а также информации о современных сербских числительных к чисто фонетической отработке двенадцуать, девятнадияать и двадцуать китайские, японские, корейские студенты перестают смешивать в речи эти числительные. В современном сербском языке и древнерусском языке до 14 века морфемное устройство числительных более прозрачно, чем в современном русском языке. Кроме того, информация об этимологии числительных сорок и девяносто оказывается интересной, по-видимому, положительные эмоции подкрепляют информационный сигнал, образуется устойчивая ассоциативная связь).

Совместить отдых и обучение помогает просмотр фильмов. Для развития восприятия речи на слух, устранения внутреннего диалога на родном языке, ускорения спонтанной речи, расширения словарного запаса, тренировки произнесения звуков и интонационных конструкций полезно повторять реплики диалогов вслух, постепенно увеличивая темп воспроизведения. Преподаватель может предложить студентам понаблюдать за особенностями коммуникации понравившегося героя фильма: артикуляцией, ритмом, тембром, рисунком жестов, дыханием, состоянием в целом, потренироваться имитировать замеченные особенности, «вжившись» в образ, проделать имитацию нескольких ключевых слов и фраз. Следующий шаг - сказать несколько фраз не из фильма, используя особенности произношения и коммуникации модели. Это упражнение может быть использовано и при постановке, корректировке и автоматизации трудного звука (например, [р], дифференциации [д] - [т] и т. п.). Помимо фильмов преподаватель использует инфографику, комиксы, различные кластеры, сравнительные диаграммы, пазлы и т. д. (Соосаар и др. 2004). Для освоения 
написания слов и развития письменной речи в целом в начале каждого урока студенты обмениваются короткими письмами, созданными на основе изученных текстов и т.д.

Об эффективности уроков РКИ свидетельствуют результаты заключительного контроля и положительные (радостные) эмоции на лицах студентов и преподавателя. Положительные эмоции студентов - залог хорошей последующей работы. Рост уровня владения русским языком, увеличение кругозора, внутренний рост студента и постоянное повышение профессионализма преподавателя - процессы связанные между собой, «катализирующие» (стимулирующие) друг друга.

\section{Использованная литература}

Капитонова, Тамара И., Московкин, Леонид В. Методика обучения русскому языку как иностранному на этапе предвузовской подготовки. СПб: Златоуст, 2006.

Кулибина, Наталья В. Художественный текст в лингводидактическом осмыслении. Москва, 2000.

Леонтьев, Алексей А. Предмет методики. Методика и её базисные науки. Психологические основы обучения русскому языку как иностранному. [В:] Методика: Заочный курс повышения квалификации филогогов-руссистов Москва, 1988: 5-6.

Попова, Елена С. «Текст и дискурс: дифференциация понятий». Молодой учёный 6, 2014: 641-643.

Соосаар, Надежда, Замковая, Наталия. Интерактивные методы преподавания. Настольная книга преподавателя. Ч.1. СПб: Златоуст, 2004.

Успенский, Михаил Б. Совершенствование методов и приёмов обучения русскому языку в национальной школе. Москва, 1970.

Федоренко, Лидия П. Принципы и методы обучения русскому языку: пособие для студентов педагогических институтов, Москва: Просвещение, 1964.

Цветкова, Зоя М. «Советская методика преподавания иностранныз языков». [В:] T.M. Дорофеева и др. (ред) Материалы международного методического семинара преподавателей русского языка стран социализма (июнь 1964 г.). Москва, 1964.

Шаховский, Виктор И. Лингвистическая теория эмоций. Москва, 2008.

Щукин, Анатолий Н. (ред.). Методика преподавания русского языка как иностранного (для зарубежных филологов-руссистов. Москва, 1990. 


\section{Светлана Чернова}

\section{О ЕФЕКТИВНОСТИ НАСТАВЕ РУСКОГ ЈЕЗИКА КАО СТРАНОГ}

\section{Резюме}

У овом раду анализирају се начини оптимизације процеса обуке страних студената руском језику: помоћ при формулисању циља наставе руског језика, повезивање наставе с позитивним емоцијама, усвајање правилног интонирања и паузирања на грађи еталонских примера руске поезије, стварање граматичких алгоритама као тачака ослонца ради успостављања нових језичких вештина, повећавање ефективности наставе путем спајања свесног и несвесног, обавезног и „случајног“, особености рада над грешкама.

Кључне речи: ефективност, циљ, емоције, примери, алгоритми, свесно и несвесно, обавезно и „случајно“, грешке. 